\title{
Pengaturan Celah Elektroda Busi Platinum dan Jenis Bahan Bakar Terhadap Konsumsi Bahan Bakar Pada Mesin 110cc
}

\author{
${ }^{1}$ Anggara Sukma Ardiyanta, ${ }^{2}$ Along Juan Subastion \\ Universitas Bhinneka PGRI, Tulungagung, Indonesia \\ Email: ${ }^{1}$ anggara@ubhi.ac.id, ${ }^{2}$ alongjuan65@gmail.com
}

\begin{tabular}{l} 
Tersedia Online di \\
\hline http://www.jurnal.unublitar.ac.id/i \\
ndex.php/briliant \\
\hline Sejarah Artikel \\
\hline Diterima pada 8 Oktober 2020 \\
Disetujui pada 7 Desember2020 \\
Dipublikasikan pada 28 Februari \\
2021 \\
Hal. 175-181 \\
\hline Kata Kunci: \\
\hline Busi Platinum; Jenis Bahan Bakar; \\
Konsumsi Bahan Bakar \\
\hline DOI: \\
\hline http://dx.doi.org/10.28926/briliant. \\
v3i4.568
\end{tabular}

Tersedia Online di

http://www.jurnal.unublitar.ac.id/i

\begin{abstract}
Abstrak: Tujuan penelitian ini menjelaskan tentang pengaturan celah elektroda busi platinum dan jenis bahan bakar serta pengaruhnya terhadap konsumsi bahan bakar. Metode penelitian menggunakan desain eksperimen dengan pendekatan one shot case study design dengan membandingkan busi platinum CR7HGP dan busi standar C7HSA, serta bahan bakar jenis Premium dan Pertalite. Hasil penelitian menunjukkan bahwa terdapat pengaruh pengaturan celah elektroda busi platinum terhadap konsumsi bahan bakar. Hasil penelitian ini menunjukkan bahwa dengan menggunakan busi platinum, dapat menurunkan konsumsi bahan bakar. Rata-rata penurunan konsumsi bahan bakar untuk celah elektroda busi 0,6mm sebesar 3\% (Premium), dan 5\% (Pertalite). Rata-rata penurunan konsumsi bahan bakar untuk celah elektroda busi 0,8mm sebesar 3\% (Premium), dan $3 \%$ (Pertalite). Rata-rata penurunan konsumsi bahan bakar untuk celah elektroda busi $1 \mathrm{~mm}$ sebesar 3\% (Premium), dan 5\% (Pertalite).
\end{abstract}

\section{PENDAHULUAN}

Busi merupakan komponen terpenting dalam sistem pembakaran, khususnya dalam mesin bensin 4 langkah dan 2 langkah. Hal ini berbeda dengan mesin Diesel, karena mesin Diesel menggunakan metode self ignition untuk menyalakan bahan bakar. Pada mesin bensin, busi sebagai pemantik, memercikkan api untuk menyalakan campuran bensin dan udara yang telah dikompresi oleh piston, sehingga tercipta konversi energi dari energi kimia, menjadi energi gerak. Energi ini kemudian diteruskan oleh pemindah tenaga menuju roda.

Terdapat beberapa jenis busi, diantaranya: (1) busi standar, (2) busi platinum, (3) busi iridium. Busi standar adalah busi yang direkomendasikan oleh pabrik pembuat mesin tersebut. Busi standar ini memiliki ujung elektroda berbahan nikel. Busi platinum adalah busi dengan ujung elektroda berbahan platinum. Ujung platinum ini memiliki ketahanan panas di atas busi standar. Busi iridium merupakan busi semi racing. Ujung elektroda terbuat dari bahan nikel dan elektroda tengah terbuat dari bahan iridium. Ketahanan panas berada di atas busi platinum (Muhamad, 2016). Dalam penelitian ini dipilih busi platinum yang memiliki kualitas menengah. 
Berdasarkan definisi busi yang telah dijelaskan, hal terpenting dari busi agar dapat bekerja, adalah adanya celah elektroda. Baik untuk busi standar, platinum maupun iridium, celah elektroda ini harus ada. Loncatan api ini terjadi, karena tegangan listrik yang besar, hingga 30.000 volt bahkan 40.000 volt. Tanpa adanya celah elektroda, bunga api tidak akan muncul, sehingga tidak terjadi pengapian. Celah elektroda busi ini dapat disesuaikan berdasarkan kebutuhan dari pengguna busi, serta kondisi mesin yang menggunakan busi. Jika celah elektroda besar, maka kebutuhan tegangan penyalaan busi juga semakin besar, dan sebaliknya (Sabar Pasaribu, 2017).

Selain busi, supaya mesin 4 langkah dan 2 langkah dapat beroperasi, perlu adanya bahan bakar. Bahan bakar untuk motor bensin, adalah bensin. Di Indonesia, bensin dibagi ke dalam beberapa kelas berdasarkan nilai oktannya (RON). Penelitian ini menggunakan jenis bahan bakar Premium RON 88 dan Pertalite 90. Bahan bakar ini dipilih dalam penelitian ini karena relatif cukup mudah di dapat di stasiun pengisian bahan bakar (SPBU). Bilangan oktan ini merupakan kemampuan bahan bakar untuk terhindar dari kemungkinan terjadinya detonasi (knocking). Semakin tinggi nilai oktan yang terkandung, maka semakin kecil kemungkinan bahan bakar tersebut terjadi detonasi, demikian pula sebaliknya (Putra \& Rosyidin, 2020)

Penggunaan jenis bahan bakar yang tepat, pemilihan dan pengaturan busi yang tepat, diharapkan akan mengasilkan konsumsi bahan bakar yang efisien. Tidak hanya pada busi, namun pada keseluruhan komponen sistem pengapian. Penggunaan busi di atas busi standar, beserta komponen sistem pengapian, dapat meningkatkan unjuk kerja motor (Putra \& Suhendri, 2018). Namun dalam penelitian ini belum menguji secara spesifik pengaturan celah elektroda busi yang optimal, agar dapat bekerja membakar campuran udara dan bahan bakar secara tuntas. Penggunaan jenis bahan dengan nilai oktan lebih tinggi, juga mampu meningkatkan nilai efisiensi volumetrik dan torsi. Penggunaan bahan bakar Premium mampu menghasilkan efisiensi volumetrik sebesar 54\% pada torsi sebesar 3Nm, sedangkan Premium menghasilkan nilai efisiensi volumetrik 34\% untuk besaran torsi yang sama (Amrullah, Sungkono, \& Prastianto, 2018).

Berdasarkan penelitian terdahulu yang telah dilakukan, maka penelitian ini bertujuan untuk mengetahui pengaruh pengaturan elektroda busi dan jenis bahan bakar, terhadap konsumsi bahan bakar. Pada penelitian ini, pengambilan data dilakukan dengan kondisi sepeda motor tetap berada pada posisinya, tidak dengan melalukan tes jalan. Pada pengambilan data awal, dengan menggunakan busi standar C7HSA dan bahan bakar jenis Premium, celah elektroda busi diatur pada 0,4 mm menghasilkan konsumsi bahan bakar sebesar 4,3 ml/menit. Berdasarkan keunggulan dari busi platinum dan penjelasan tentang bahan bakar, diharapkan dengan menggunakan oktan bahan bakar lebih tinggi, celah elektroda busi lebih renggang, dan spesifikasi busi di atas busi standar, akan menghasilkan konsumsi bahan bakar $\leq 4,3 \mathrm{ml} / \mathrm{menit}$.

\section{METODE}

Penelitian ini menggunakan metode eksperimen dengan pendekatan one shot case study. Pendekatan ini merupakan pengambilan data secara langsung 
setelah melakukan pengukuran (Sugiyono, 2015). Sebagaimana dijelaskan dalam Gambar 1 berikut:

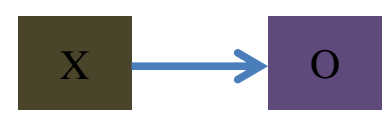

Gambar 1. Pendekatan One Shot Case Study

Variabel dalam penelitian ini terdiri dari variabel bebas, variabel terikat dan variabel kontrol.

1. Variabel bebas dalam penelitian ini adalah celah elektroda busi. Celah elektroda busi diatur dalam ukuran $0,6 \mathrm{~mm}, 0,8 \mathrm{~mm}, 1 \mathrm{~mm}$

2. Variabel kontrol dalam penelitian ini adalah jenis bahan bakar, yaitu Premium RON88 dan Pertalite RON90. Waktu pengukuran dikondisikan selama 5 menit.

3. Variabel terikat dalam penelitian ini adalah konsumsi bahan bakar.

4. Variabel moderator dalam penelitian ini adalah besaran RPM.

Adapun langkah dalam penelitian ini dapat digambarkan pada diagram alir berikut:

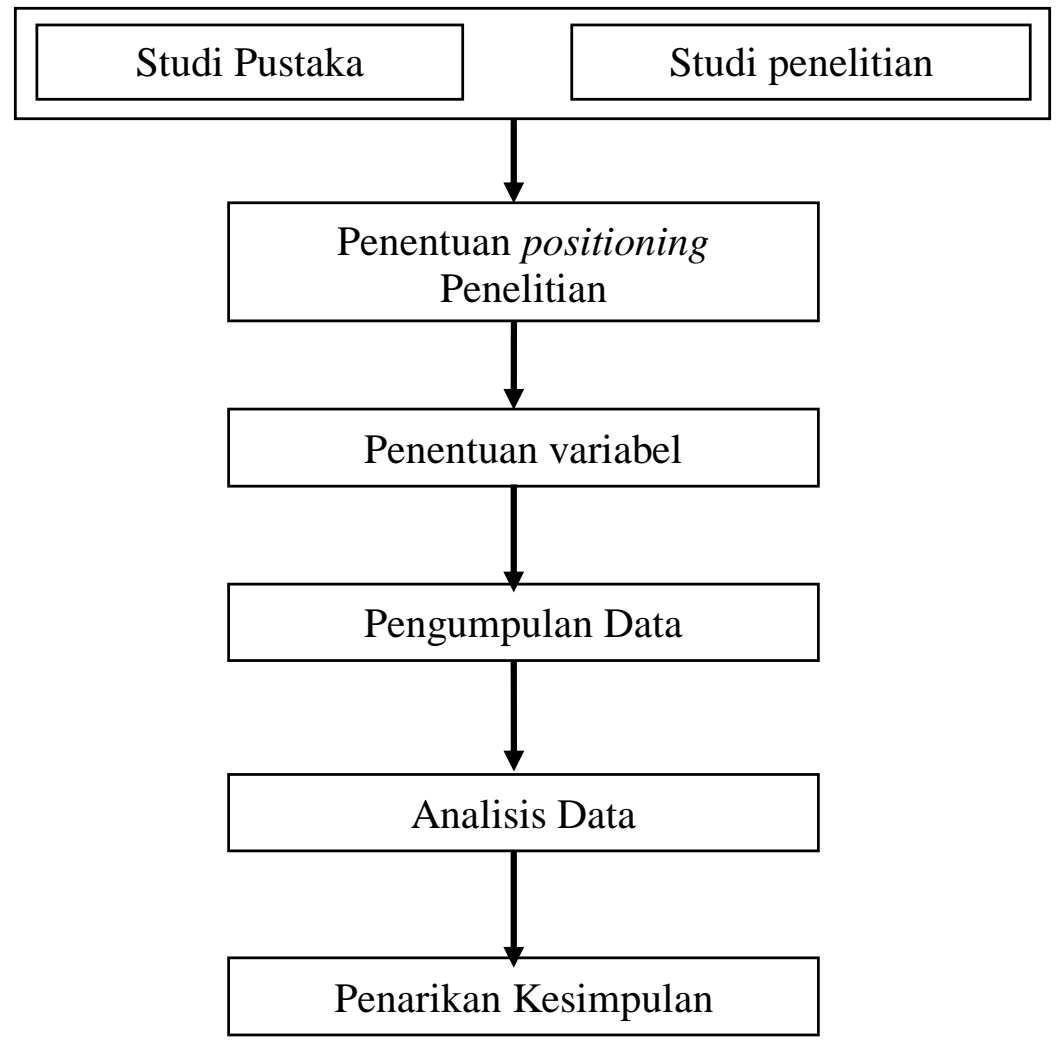

Gambar 2. Tahapan Penelitian

Instrumen yang digunakan dalam penelitian:

1. Unit Sepeda Motor 110cc dengan sistem bahan bakar karburator

2. Gelas ukur untuk menakar jumlah bahan bakar 
3. Tachometer untuk mengukur RPM

4. Busi platinum NGK G Power CR7HGP

5. Busi standar NGK C7HSA

6. Bahan bakar Premium dan Pertalite

7. Stop watch untuk mengatur waktu pengambilan data

8. Peralatan tangan (hand tools)

9. Feeler gauge untuk mengukur celah elektroda busi

Analisis data menggunakan statistik deskriptif. Hasil pengukuran ditampilkan dalam bentuk tabel, selanjutnya dilakukan analisis dan pembahasan. Analisis data dapat dideskripsikan melalui Tabel 1 berikut:

Tabel 1. Alur Kerja Pengambilan Data dan Analisis Data

\begin{tabular}{|l|l|l|l|l|}
\hline No & $\begin{array}{l}\text { Jenis Bahan } \\
\text { Bakar }\end{array}$ & $\begin{array}{l}\text { Celah Elektroda } \\
\text { Busi Platinum } \\
\text { dan Standar }\end{array}$ & $\begin{array}{l}\text { Variasi } \\
\text { Putaran Mesin } \\
\text { (Rpm) }\end{array}$ & $\begin{array}{l}\text { Konsumsi } \\
\text { Bahan Bakar }\end{array}$ \\
\hline 1 & Premium & $0,6 \mathrm{~mm}$ & 2000 & $\mathrm{ml} / \mathrm{menit}$ \\
\cline { 3 - 5 } 2 & Pertalite & $0,8 \mathrm{~mm}$ & 3000 & $\mathrm{ml} / \mathrm{menit}$ \\
\cline { 3 - 5 } & & $1 \mathrm{~mm}$ & 4000 & $\mathrm{ml} / \mathrm{menit}$ \\
\hline 3 & &
\end{tabular}

\section{HASIL}

Pengambilan data dilakukan saat mesin dalam keadaan diam di tempat (tidak sedang beroperasi di jalan). Hasil penelitian dapat ditunjukkan dalam Tabel 2 sampai tabel 4, berdasarkan rentang 2000 RPM, 3000 RPM, dan 4000 RPM.

Tabel 2. Konsumsi Bahan Bakar pada 2000 RPM

\begin{tabular}{|c|c|c|c|c|c|c|c|}
\hline \multirow{5}{*}{$\begin{array}{l}\mathrm{RP} \\
\mathrm{M}\end{array}$} & \multirow{4}{*}{$\begin{array}{l}\text { Celah } \\
\text { Elektrod } \\
\text { a Busi }\end{array}$} & \multicolumn{4}{|c|}{ Jenis Bahan Bakar } & \multicolumn{2}{|c|}{ Persentase } \\
\hline & & \multicolumn{2}{|c|}{ Premium } & \multicolumn{2}{|c|}{ Pertalite } & \multirow{3}{*}{$\begin{array}{l}\text { Premiu } \\
\mathrm{m}\end{array}$} & \multirow{3}{*}{$\begin{array}{l}\text { Pertalit } \\
\mathrm{e}\end{array}$} \\
\hline & & $\begin{array}{l}\text { C7HS } \\
\text { A }\end{array}$ & $\begin{array}{l}\text { CR7HG } \\
\mathrm{P}\end{array}$ & $\begin{array}{l}\text { C7HS } \\
\text { A }\end{array}$ & $\begin{array}{l}\text { CR7HG } \\
\mathrm{P}\end{array}$ & & \\
\hline & & $\mathrm{BBM}$ & BBM & $\mathrm{BBM}$ & $\mathrm{BBM}$ & & \\
\hline & $\mathrm{mm}$ & $\mathrm{ml} / \mathrm{mnt}$ & $\mathrm{ml} / \mathrm{mnt}$ & $\mathrm{ml} / \mathrm{mnt}$ & $\mathrm{ml} / \mathrm{mnt}$ & $\mathrm{ml} / \mathrm{mnt}$ & $\mathrm{ml} / \mathrm{mnt}$ \\
\hline \multirow{3}{*}{2000} & 0,6 & 3,9 & 3,8 & 3,6 & 3,5 & $3 \%$ & $3 \%$ \\
\hline & 0,8 & 3,8 & 3,6 & 3,2 & 3 & $5 \%$ & $6 \%$ \\
\hline & 1 & 3,9 & 3,8 & 3,4 & 3,5 & $3 \%$ & $-3 \%$ \\
\hline
\end{tabular}

Tabel 3. Konsumsi Bahan Bakar pada 3000 RPM

\begin{tabular}{|c|c|c|c|c|c|c|c|}
\hline \multirow{5}{*}{$\begin{array}{l}\mathrm{RP} \\
\mathrm{M}\end{array}$} & \multirow{4}{*}{$\begin{array}{l}\text { Celah } \\
\text { Elektrod } \\
\text { a Busi }\end{array}$} & \multicolumn{4}{|c|}{ Jenis Bahan Bakar } & \multicolumn{2}{|c|}{ Persentase } \\
\hline & & \multicolumn{2}{|c|}{ Premium } & \multicolumn{2}{|c|}{ Pertalite } & \multirow{3}{*}{$\begin{array}{l}\text { Premiu } \\
\mathrm{m}\end{array}$} & \multirow{3}{*}{$\begin{array}{l}\text { Pertalit } \\
\mathrm{e}\end{array}$} \\
\hline & & $\begin{array}{l}\text { C7HS } \\
\text { A }\end{array}$ & $\begin{array}{l}\text { CR7HG } \\
P\end{array}$ & $\begin{array}{l}\text { C7HS } \\
\text { A }\end{array}$ & $\begin{array}{l}\text { CR7HG } \\
\mathrm{P}\end{array}$ & & \\
\hline & & BBM & BBM & BBM & BBM & & \\
\hline & $\mathrm{mm}$ & $\mathrm{ml} / \mathrm{mnt}$ & $\mathrm{ml} / \mathrm{mnt}$ & $\mathrm{ml} / \mathrm{mnt}$ & $\mathrm{ml} / \mathrm{mnt}$ & $\mathrm{ml} / \mathrm{mnt}$ & $\mathrm{ml} / \mathrm{mnt}$ \\
\hline 3000 & 0,6 & 6,5 & 6,4 & 6,3 & 6 & $2 \%$ & $5 \%$ \\
\hline
\end{tabular}




\begin{tabular}{|l|l|l|l|l|l|l|l|}
\hline & 0,8 & 6,3 & 6,3 & 5,8 & 5,8 & $0 \%$ & $0 \%$ \\
\cline { 2 - 7 } & 1 & 6,4 & 6,4 & 6,4 & 6 & $0 \%$ & $6 \%$ \\
\hline
\end{tabular}

Tabel 4. Konsumsi Bahan Bakar pada 4000 RPM

\begin{tabular}{|c|c|c|c|c|c|c|c|}
\hline \multirow{5}{*}{$\begin{array}{l}\mathrm{RP} \\
\mathrm{M}\end{array}$} & \multirow{4}{*}{$\begin{array}{l}\text { Celah } \\
\text { Elektrod } \\
\text { a Busi }\end{array}$} & \multicolumn{4}{|c|}{ Jenis Bahan Bakar } & \multicolumn{2}{|c|}{ Persentase } \\
\hline & & \multicolumn{2}{|c|}{ Premium } & \multicolumn{2}{|c|}{ Pertalite } & \multirow{3}{*}{$\begin{array}{l}\text { Premiu } \\
\mathrm{m}\end{array}$} & \multirow{3}{*}{$\begin{array}{l}\text { Pertalit } \\
\text { e }\end{array}$} \\
\hline & & $\begin{array}{l}\text { C7HS } \\
\text { A }\end{array}$ & $\begin{array}{l}\text { CR7HG } \\
\mathrm{P}\end{array}$ & $\begin{array}{l}\text { C7HS } \\
\text { A }\end{array}$ & $\begin{array}{l}\text { CR7HG } \\
\mathrm{P}\end{array}$ & & \\
\hline & & $\mathrm{BBM}$ & BBM & $\mathrm{BBM}$ & $\mathrm{BBM}$ & & \\
\hline & $\mathrm{mm}$ & $\mathrm{ml} / \mathrm{mnt}$ & $\mathrm{ml} / \mathrm{mnt}$ & $\mathrm{ml} / \mathrm{mnt}$ & $\mathrm{ml} / \mathrm{mnt}$ & $\mathrm{ml} / \mathrm{mnt}$ & $\mathrm{ml} / \mathrm{mnt}$ \\
\hline \multirow{3}{*}{4000} & 0,6 & 12,6 & 12 & 11,5 & 10,5 & $5 \%$ & $9 \%$ \\
\hline & 0,8 & 12 & 11,5 & 10,4 & 10 & $4 \%$ & $4 \%$ \\
\hline & 1 & 12,4 & 11,7 & 11,5 & 10,2 & $6 \%$ & $11 \%$ \\
\hline
\end{tabular}

Tabel 5. Persentase Rata-rata Penurunan Konsumsi Bahan Bakar

\begin{tabular}{|l|l|l|l|}
\hline \multirow{2}{*}{ No } & \multirow{2}{*}{\begin{tabular}{l} 
Ukuran Celah Elektroda \\
\cline { 3 - 4 }
\end{tabular}} & \multicolumn{3}{|l|}{ Bahan Bakar } \\
\cline { 3 - 4 } & 0,6 & 3 & 5 \\
\hline 2 & 0,8 & 3 & 3 \\
\hline 3 & 1 & 3 & 5 \\
\hline
\end{tabular}

\section{PEMBAHASAN}

Hasil penelitian pada Tabel 2, Tabel 3, dan Tabel 4 menunjukkan bahwa perbedaan konsumsi bahan bakar, baik untuk kombinasi Premium-C7HSA, Premium-CR7HGP, Pertalite-C7HSA, dan Pertalite-CR7HGP relatif tidak signifikan. Hasil ini disebabkan karena sistem pemasukan bahan bakar pada sepeda motor masih menggunakan sistem karburator. Hal ini sangat berbeda dengan sistem elektronik, bahwa sistem pemasukan dikontrol secara elektronik melalui ECU. Jika menggunakan karburator, throttle valve masih dibuka secara manual dengan tangan, dan pemasukan bahan bakar mengandalkan kevakuman dari hisapan piston, serta besar kecilnya main jet dan pilot jet. Pengabutan pada sistem karburator tidak sehalus sistem injeksi elektronik. Selain itu, terdapat berbagai variabel yang mengatur kebutuhan bahan bakar yang diperlukan untuk pembakaran (Saharuna, 2017).

Pada pengaturan celah elektroda busi C7HSA yang relatif sempit $(0,6 \mathrm{~mm})$, konsumsi bahan bakar cenderung relatif lebih banyak, daripada celah elektroda busi $0,8 \mathrm{~mm}$. Hal ini terjadi, karena api yang dihasilkan busi lebih kecil, sehingga pembakaran menjadi kurang maksimal, sehingga untuk mengimbanginya, throttle valve harus terbuka lebih besar yang berakibat konsumsi bahan bakar relatif lebih banyak. Pada pengaturan celah elektroda ini, terdapat keuntungan yaitu kebutuhan tegangan pengapian menjadi lebih rendah karena celah elektroda busi sempit. Busi platinum CR7HGP memiliki keunggulan pengapian yang lebih besar, untuk celah elektroda busi yang sama. Dengan keunggulan ini, mampu mereduksi konsumsi bahan bakar daripada busi C7HSA. 
Pada pengaturan celah elektroda busi sebesar $0,8 \mathrm{~mm}$ baik untuk busi C7HSA dan busi platinum CR7HGP, menghasilkan konsumsi bahan bakar terendah pada putaran mesin yang sama. Hal ini terjadi karena pada celah elektroda sebesar 0,8 mm merupakan celah elektroda busi terbaik, dimana pada pengaturan ini, tidak terjadi missfire. Pada celah elektroda busi $0,8 \mathrm{~mm}$ baik untuk busi standar C7HSA dan CR7HGP membutuhkan tegangan penyalaan yang relatif lebih rendah, daripada celah elektroda busi $0,6 \mathrm{~mm}$ dan $1 \mathrm{~mm}$ (Suwandono, Rusnoto, \& Hidayatulloh, 2011),

Pada pengaturan celah elektroda busi C7HSA sebesar $1 \mathrm{~mm}$, konsumsi bahan bakar cenderung meningkat. Celah elektroda busi yang relatif renggang mengakibatkan kebutuhan tegangan penyalaan relatif lebih tinggi, peningkatan temperatur dan tekanan dalam silinder mesin (Badawy, Bao, \& $\mathrm{Xu}, 2017$ ). Meskipun telah menggunakan busi platinum CR7HGP, pada pengaturan celah elektroda $1 \mathrm{~mm}$ terjadi missfire, sehingga berdampak pada konsumsi bahan bakar yang lebih besar. Missfire (knalpot meletup) terjadi karena bahan bakar tidak habis terbakar, atau tidak terjadi pembakaran di dalam silinder, akan tetapi terjadi di knalpot. Hal ini terjadi karena mesin yang digunakan masih menggunakan sistem pengapian standar, sehingga perlu dilakukan peningkatan (upgrade).

Penelitian ini merupakan penelitian laboratorium, serta kondisi sepeda motor tanpa beban buatan dan tanpa tes jalan. Selain busi dan jenis bahan bakar terdapat faktor lain, yang mempengaruhi konsumsi bahan bakar, seperti kebiasaan mengemudi/berkendara, pengaturan celah katup hisap dan buang, beban buatan yang dibawa, kondisi medan jalan, serta jenis transmisi yang digunakan (Budiharto \& Priangkoso, 2013).

\section{KESIMPULAN}

Dari hasil penelitian, analisis data, serta pembahasan yang telah dijelaskan, maka dapat ditarik kesimpulan bahwa, terdapat pengaruh pengaturan celah elektroda busi platinum dan jenis bahan bakar terhadap konsumsi bahan bakar. Penggunaan busi platinum dapat menurunkan konsumsi bahan bakar.

Pada putaran mesin 2000 RPM, konsumsi bahan bakar terendah sebesar 3 $\mathrm{ml} / \mathrm{mnt}$ pada celah elektroda busi platinum $0,8 \mathrm{~mm}$. Pada putaran mesin $3000 \mathrm{RPM}$, konsumsi bahan bakar terendah sebesar $5,8 \mathrm{ml} / \mathrm{mnt}$ pada celah elektroda busi 0,8 $\mathrm{mm}$. Pada putaran mesin 4000 RPM, konsumsi bahan bakar terendah sebesar 10 $\mathrm{ml} / \mathrm{mnt}$ pada celah elektroda busi $0,8 \mathrm{~mm}$.

Rata-rata penurunan konsumsi bahan bakar untuk celah elektroda busi 0,6mm sebesar 3\% (Premium), dan 5\% (Pertalite). Rata-rata penurunan konsumsi bahan bakar untuk celah elektroda busi $0,8 \mathrm{~mm}$ sebesar 3\% (Premium), dan 3\% (Pertalite). Rata-rata penurunan konsumsi bahan bakar untuk celah elektroda busi $1 \mathrm{~mm}$ sebesar 3\% (Premium), dan 5\% (Pertalite).

\section{SARAN}

Berdasarkan kesimpulan yang telah ditarik, maka peneliti mengajukan saran/rekomendasi, yaitu sebaiknya dilakukan pengujian dengan cara tes jalan (road tes) sehingga konsumsi bahan bakar akan lebih aktual. Hasil penelitian ini masih memerlukan uji coba pada sepeda motor yang berbeda. Penelitian ini merupakan penelitian yang sulit digeneralisasi, karena pada dasarnya, kondisi 
setting dan kondisi sepeda motor antara satu dan lainnya bisa berbeda. Penelitian selanjutnya dapat difokuskan pada hubungan pemilihan heat range busi yang sesuai dengan jenis bahan bakar yang digunakan.

\section{DAFTAR RUJUKAN}

Amrullah, Sungkono, \& Prastianto, E. (2018). Analisis Pengaruh Penggunaan Bahan Bakar Premium dan Pertamax terhadap Prestasi Mesin. Teknologi, 18(1), 24.

Badawy, T., Bao, X., \& Xu, H. (2017). Impact of spark plug gap on flame kernel propagation and engine performance. Applied Energy, 191, 311-327.

Budiharto, M., \& Priangkoso, T. (2013). Hubungan Jenis Bahan Bakar dengan Konsumsi Bahan Bakar Sepeda Motor Bertransmisi CVT, Semi-Otomatik, dan Manual. Jurnal Momentum, 9(2), 22-24.

Muhamad, Z. (2016). Pengaruh Penggunaan Jenis Busi terhadap Unjuk Kerja (Performance) Motor Bensin Empat Langkah (Four Stroke). Penelitian Universitas Bandar Lampung.

Putra, R. C., \& Rosyidin, A. (2020). Pengaruh Nilai Oktan terhadap Unjuk Kerja Motor Bensin dan Konsumsi Bahan Bakar dengan Busi-Koil Standar-Racing. Jurnal Polimesin, 18(1), 7-15.

Putra, R. C., \& Suhendri, A. (2018). Perbandingan Unjuk Kerja dan Konsumsi Bahan Bakar antara Motor yang Mempergunakan Koil Standar dan Busi Standar dengan Motor yang Mempergunakan Koil Racing dan Busi Racing Menggunakan Bahan Bakar Pertamax. Motor Bakar: Jurnal Teknik Mesin Universitas Muhammadiyah Tangerang, 2(1), 1-6.

Sabar Pasaribu. (2017). Pengaruh Variasi Celah Busi Dan Jenis Busi Terhadapemisi Gas Buang Pada Kendaraan Roda Dua 110cc. Jurnal Ilmiah "INTEGRITAS," 3(1), 25-38.

Saharuna. (2017). Perbandingan Konsumsi Bahan Bakar Sepeda Motor Sistem Konvensional dan Sistem EFI. Jurnal Teknologi, 19(1), 34-42.

Sugiyono. (2015). Metode Penelitian Kuantitatif Kualitatif dan R\&D. Bandung: Alfabeta.

Suwandono, Rusnoto, \& Hidayatulloh, T. (2011). Analisa Celah Busi terhadap Konsumsi Bahan Bakar Beijing 100cc. 